\title{
El signo de los tiempos como categoría teórica
}

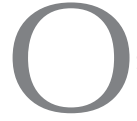
rientarse en la compleja situación presente, tratar de proyectarse hacia el futuro, desentrañar el horizonte actual de posibilidades, requiere de un conocimiento y análisis del pasado reciente. En definitiva, de un esfuerzo de comprensión y asimilación del proceso histórico. Captar la lógica que ha presidido la cadena de acontecimientos, a menudo a despecho de las intenciones y propósitos de quienes los protagonizaron. No es fácil. Requiere de un trabajo reflexivo, analítico y teórico. Precisa, además, de una actitud que permita un cierto distanciamiento, no tanto sobre el material histórico como sobre los propios prejuicios e ideas preconcebidas, de los que no están libres ni el lector ni el investigador.

Lo más importante: se necesita de herramientas teóricas y conceptuales acordes con el material histórico que se trata de desentrañar. Esta puede ser una gran dificultad. En nuestros países latinoamericanos muy a menudo se intentan aplicar metodologías y aparatos teóricos que no encajan con nuestra realidad. No se advierte que si la teoría no resulta adecuada es justamente por haber sido desarrollada en otras latitudes o en otras épocas. Si hay desajuste entre la parte teórica y la práctica, es ésta última la que debería ser preservada y la teoría la que debe revisarse. Pero no siempre se hace así. Con frecuencia se tiende a forzar los hechos, a falsear la realidad histórica, para que se ajuste a lo que dicta la teoría.

Se olvida entonces que siempre y en todas partes la teoría es desarrollada a partir de la práctica. En el caso de la historia nuevos desarrollos teóricos han surgido de procesos reales novedosos, distintos, que necesitaban de herramientas conceptuales y teóricas diferentes a las que se disponía en el momento. En nuestro caso ocurre igual. Hay que superar el complejo de inferioridad y la tendencia a las distintas variedades de dependencia intelectual. Debemos dar el paso y atrevernos a pensar por nosotros mismos. Conceptualizar lo nuestro y desarrollar nuestros propios aportes a la teoría. 
En el caso de El Salvador hay que decir que nuestro déficit teórico es escandaloso. Un proceso histórico sumamente intenso y novedoso, "diferente" en muchos aspectos, innovador y creativo en sus realizaciones, sin embargo permanece huérfano de una reflexión e interpretación que esté a la altura de aquella novedad radical. Así como se afirma que no hay práctica revolucionaria sin teoría revolucionaria, debe valer la afirmación contraria. Si el caso salvadoreño ha sido revolucionario y transformador en muchos sentidos, lo lógico sería que también genere aportes y transformación en el terreno teórico. La innovadora praxis histórica debe encontrar su correlato en las correspondientes innovaciones en la teoría. Pensar este concreto proceso histórico, su complejidad y especificidad, y tratar de pensarlo hasta el final. De eso se trata. Es el desafío al que este material trata de responder y el espíritu que animó a su autor.

En este sentido, el artículo es sin duda "muy salvadoreño". No obstante, tiene vocación universal. La teoría es siempre de carácter y validez universal, aunque tenga su punto de partida en lo concreto y particular. Los grandes textos clásicos de la ciencia histórica han llegado a serlo, justamente, por haberse ocupado de la concreción de un proceso histórico determinado.

\section{Los tiempos han cambiado}

Hemos cambiado nuestra conciencia de la historia, nuestra visión del pasado, tal como siempre pasa y seguirá ocurriendo. La ideología ha cambiado y lo expresamos diciendo que ésta es otra época. Éstos de ahora son otros tiempos. Cualquiera puede darse cuenta, cualquiera puede afirmarlo. Tal vez sin mayor reflexión. Parece algo claro y evidente. Pero no lo es en absoluto. "Los tiempos han cambiado." En esta frase se encierra toda la complejidad de un proceso histórico. ¿Por qué el cambio? ¿En qué consiste? ¿Cómo se ha producido? ¿Qué tanto nos condiciona? Hay una auténtica problemática teórica e histórica escondida tras aquella inocente frase.
Las preguntas son importantes al momento de intentar comprender mejor nuestro presente. Pero sobre todo en un proceso histórico como el salvadoreño en el que la dimensión del cambio es tan grande. ¡En los últimos cuarenta años El Salvador ha pasado por tantas cosas! Ha habido de todo. En 1969, arranque de nuestro estudio, encontramos la guerra con un país vecino. Tras el conflicto armado con Honduras, una severa crisis social y política. Partido oficial, oposición legalizada, guerrillas, organizaciones populares, fraudes electorales, protestas, huelgas, manifestaciones, masacres... Toda una década de mucha inquietud y gran actividad política. Des- 
pués, un golpe de estado que puso fin al régimen político de dictadura militar. Le sigue un confuso período en el que fracasa el reformismo y también la estrategia insurreccional. Se desencadena así una guerra civil que durará doce años. Tras el largo y sangriento conflicto interno, la solución por la vía negociada.

De esta forma, en la última década del siglo $X X$, se abre en el país un nuevo escenario de paz y democracia. Aunque incipiente y frágil, incluso insatisfactoria en muchos sentidos, la transición democrática por la que atraviesa El Salvador constituye una situación inusitada, una agradable sorpresa, respecto lo que ha sido su historia desde que la nación alcanzó su independencia. La posguerra salvadoreña ha sido sorprendentemente exitosa en el área de los acuerdos militares y profundamente transformadora en lo político. Ha llevado a que el caso salvadoreño sea tomado por la comunidad internacional como un modelo para el mundo.

Sin embargo, para la población que la vive en El Salvador, la transición resulta una etapa histórica con muchas sombras. No está claro de qué tipo de transición se trata. Mucho menos, para dónde va y qué orientación tiene. La población -mucho más crítica que la mayoría de analistas y dirigentes- refleja preocupación por el presente e incertidumbre por el futuro. Pero en algo el consenso es unánime: nadie desea regresar a los tiempos de confrontación.

Tan es así que se propagandizó el esfuerzo consciente por superar y apartarse del período del conflicto como desideologización. Al poco que se examine se advertirá que la pretendida desideologización no es sino expresión de la ideología preponderante tras la firma de los acuerdos de paz. Es la ideología que pretende no serlo. Pero resulta interesante pues remite a la nueva manera en que los protagonistas miran ahora hacia su propio pasado. Hay en esa mirada un reconocimiento de lo que en su momento pasó inadvertido: el grado de ideologización extremo en que el país había entrado. Así pues, la nueva ideología de la desideologización es capaz de mostrarnos con bastante objetividad la etapa anterior de sobreideologización, de la cual no es sino el reverso de la medalla, su negación dialéctica.

Debe destacarse que la postulada desideologización no debe tomarse como sinónimo de despolitización. Lo que hay en El Salvador de posguerra no es despolitización. Esta la hay en países donde la población ha vivido ajena a la política, de espaldas a ella. No es, en absoluto, el caso de El Salvador. En pocas partes se ha vivido la política con tanta pasión e intensidad. Lo que ahora ha sobrevenido es una variedad de desencanto de la política. Incredulidad, desengaño, apatía. 
Pero no hay falta de interés por la política, tal como lo demuestra la cantidad de programas informativos y de opinión en los medios de comunicación. La gente común y corriente entiende y discute de política. Tampoco es usual en El Salvador encontrar ingenuidad política, tan típica en poblaciones de países del primer mundo.

El tema del "desencanto" nos remite al cambio en la relación entre líderes y masas, dirigentes y dirigidos. Es decir, el Ilamado "cansancio de la guerra" terminó expresando una modalidad de cansancio hacia la política y respecto los políticos. La incapacidad de las dirigencias por concluir el conflicto inició ese distanciamiento que ahora se expresa en la posguerra como desengaño y distanciamiento. Hay desconfianza en la llamada "clase política". Es un fenómeno que se presenta como típico de la transición y que propicia una serie de interrogantes sobre el futuro del proceso.

En todo caso queda enfatizada la afirmación inicial de este fragmento: los tiempos han cambiado, política e ideológicamente. Resulta imprescindible emprender la revisión y reflexión sobre la historia reciente del país para captar a plenitud la dimensión del cambio y su orientación. Igualmente para entender cómo ese intenso proceso histórico nos ha transformado, como país y como personas.

\section{La historia como proceso}

La historia la hacen los hombres, pero también es verdad que la historia hace a los hombres. Los seres humanos presentan así un doble carácter: por un lado son sujetos de la historia, pero por otro lado aparecen como objeto de la misma. En este segundo punto de vista el proceso histórico es percibido como algo externo, objetivo, como parte de la realidad con la que debemos contar. No sólo eso. El proceso se nos impone. Es lo que el filósofo español Xabier Zubiri llama la poderosidad de lo real. La realidad tiene fuerza de imposición sobre el ser humano. Igualmente ocurre con esa parcela de la realidad que es la realidad histórica.
Hacemos la historia, es cierto, pero también estamos en ella, es parte del mundo real en el que estamos y al que pertenecemos. En la medida que los seres humanos estamos en la historia y somos resultado de ella, ésta toma la apariencia de algo exterior, como algo que tiene su propia lógica, su propia dinámica, a la cual debemos acoplarnos. De ahí que el proceso histórico aparezca en su objetividad como algo con su propia independencia y que estamos obligados a conocer y comprender si pretendemos llegar a dominarlo. El dirigente termina aceptando esa situación y reconociendo que su propia actuación en 
la historia le permite ir entendiendo cada vez mejor el proceso histórico en el que actúa y a modular su acción en función de las posibilidades y potencialidades del proceso.

Lo real se presenta al ser humano como un campo abierto de posibilidades $y$, por ello mismo, también de imposibilidades. Para el hombre de acción, reconocer las limitaciones que le impone el proceso histórico en el que participa no significa anular su libre accionar sino modificar éste para que resulte realista, acorde con las posibilidades concretas que el proceso real abre frente a él. De tal modo, el proceso histórico realiza una propedéutica sobre sus agentes, desarrolla una pedagogía sobre los líderes históricos, consiguiendo que entiendan que la historia no es simple fruto de la libre voluntad, sino modulada por la presencia de la necesidad y de la posibilidad. La libertad en la historia resulta así reducida a un ejercicio de escogencia entre un número limitado de posibilidades. En el fondo, se hace lo que se puede.

El dirigente, al reconocer humildemente su limitación eleva su accionar a un plano mucho más consciente y de mayor responsabilidad al que reflejaba cuando pretendía ingenuamente que todo podía ser alcanzado si se ponía en ello suficiente empeño, que podía "ir al asalto del cielo", o sea, bajar el cielo a la tierra y transformar ésta en el particular paraíso por él soñado.
La dureza de la realidad, que no se ablanda con los sueños humanos, debe primero ser conocida y reconocida para poder ser luego moldeada según la inspiración de aquellos sueños. El proceso real impone así una lección de realismo y objetividad que se opone y atenúa las voluntades subjetivas, el utopismo y las dosis de idealismo que predominan en los sujetos humanos durante un primer período. Este triunfo del proceso objetivo es parte de lo que se apreciará más tarde como resultado del mismo. La transformación en las percepciones, ideología y conciencia histórica, como síntoma de la madurez con que los actores culminan un período histórico.

Lo real se ha impuesto sobre lo ideal, tanto en el proceso objetivo como en la conciencia humana. No necesariamente suprimiéndolo, pero sí sometiéndolo y cambiándolo, para que se ajuste a lo que podemos denominar el ideal realista. El ideal no ha desaparecido, pero ha dejado de estar contrapuesto a lo real como una contradicción insalvable. Se mantiene siempre en tensión con la realidad, mas en una dialéctica donde la contradicción es superable y se reconcilia en el realismo del ideal. Este realismo es positivo y transformador en la medida que permite el cambio posible de la realidad y deja de confrontarla con pretensiones que son imposibles.

Esa misma transformación en la conciencia y conocimiento del pro- 
ceso opera sin duda sobre el historiador que se enfrenta a su material de investigación en ese momento de realismo que le permite un mayor grado de objetividad. Pero además le posibilita partir del elemento objetivo que está contenido en el proceso. De alguna forma ése será ahora tratado como el verdadero sujeto de la historia. Efectivamente, en la medida que trata a los hombres como objetos de la historia ésta muestra el rostro de un proceso sin sujeto, o lo que es lo mismo, una historia en la que el proceso es el sujeto. Es el punto de vista de la objetividad del proceso que se impone sobre la subjetividad humana, que habrá de ser completado después por el punto de vista contrario, pero que debe ser tomado como el punto de partida para el análisis histórico.

Lo primero será descubrir en el conjunto de acontecimientos el nexo que los identifica como formando parte de un proceso. Es decir, si la historia es proceso significa que los hechos históricos no están desligados unos de otros, no son cosas independientes que podamos revisar por separado, sino que existe un vínculo que los relaciona. Éste deberá ser descubierto y mostrado, es decir, des-cubierto. Pero además, afirmar que la historia es proceso implica asimismo que el dinamismo de los acontecimientos genera auténtico movimiento en eso que Ilamamos historia. Genera un proceso, es decir, un movimiento histórico con las características propias de lo que se mueve: una dirección u orientación, una determinada velocidad o ritmo histórico.

La historia como proceso aparece capaz de sufrir avances y retrocesos, virajes y oscilaciones, aceleraciones y frenazos. El proceso es la forma de presentación del tiempo histórico el cual, al igual que la música, tiene su propio tempo, es decir, su ritmo. La apreciación de esos elementos por el investigador puede parecer algo bastante subjetivo, sin embargo es parte de lo que "está ahí", es parte de la objetividad del proceso histórico concreto. Igualmente con respecto a la periodización del proceso. Dependiendo del punto de vista del historiador, de lo que esté buscando, establecerá diferentes períodos. Por ejemplo, nuestra periodización del proceso salvadoreño no va a ser la misma si lo estamos examinando desde el punto de vista de la guerra civil que se estaba desarrollando que si lo hacemos desde la perspectiva de la paz negociada que pudo obtenerse al final. Podemos así establecer diferentes periodizaciones del mismo proceso.

No obstante, nada de esto resulta artificialmente puesto por el historiador. La periodización está ahí, pertenece al proceso objetivo, debe ser descubierta por el investigador. Es decir, es constitutiva del carácter de proceso que tiene en sí la historia. Todo proceso, por serlo, se compone de etapas o períodos. Le corresponde la imagen de una 
escalera, que es única y a la vez podemos considerar compuesta por escalones sucesivos, que han de ser examinados uno a uno.

La imagen de la escalera resulta bastante conveniente porque, como en ella, también el proceso presenta una secuencia de etapas, unas gradas, que son sucesivas y arrancan cada una de la anterior. Forzamos la lógica de la escalera si saltamos peldaños y asimismo forzaríamos la lógica del proceso si no mostramos el encadenamiento de cada fase con la siguiente. La misma imagen paralela nos sirve para reflejar la idea de movimiento, ascendente o descendente, que sugieren tanto una escalera como el proceso histórico. Seguir su recorrido, su movimiento, fase a fase y peldaño a peldaño para, en ambos casos, revisar adonde nos conducen.

\section{El proceso histórico como proceso dialéctico}

El que la historia sea proceso no necesariamente implica que éste sea de naturaleza dialéctica. Es más, algunos colegas están completamente en contra. No hace mucho uno de ellos criticaba enérgicamente el método de análisis dialéctico de la historia, pues en su opinión tiene cosas ridículas como la idea de que se den saltos cualitativos. "Lo único que salta son las ranas", afirmaba rotundo. En lo personal esta apreciación me parece errada desde distintos puntos de vista. En primer lugar, si se toma de manera textual, la frase es claramente falsa. No sólo las ranas saltan. También lo hacen los sapos. $\mathrm{Y}$ muchos otros animalitos: las pulgas, los saltamontes o esperanzas, las langostas, los canguros, las liebres, los conejos, etc.

Sin dejar el terreno de la zoología, cabría preguntarse si el colega no estaría dispuesto a aceptar la idea del salto cualitativo en el caso de las feas orugas, que después de un tiempo en el capullo se transforman en bellas mariposas. Aquello que se arrastraba torpemente nos sorprende en un momento posterior alzándose en maravilloso vuelo. Y sin embargo sigue siendo el mismo animal, aunque simultáneamente y de manera muy evidente, ya no es el mismo.

Cada cosa es idéntica a sí misma, $A=A$, afirma la lógica tradicional; sin embargo en este ejemplo encontramos una lógica diferente: A es igual a sí mismo y al mismo tiempo es diferente de sí. Es el principio de la lógica dialéctica que Hegel enunciaba como la identidad entre la identidad y la no identidad. La cosa sigue siendo ella misma, permanece idéntica a sí, pero a la vez ya no es igual, ha cambiado, se ha transformado y es diferente a sí misma, sin dejar de ser ella. La lógica tradicional que excluye la contradicción puede explicar la inmutabilidad de una piedra pero es 
incapaz de penetrar en la lógica de la vida, pues lo esencial del viviente es el cambio y la transformación continuos. La inmutabilidad e identidad absoluta consigo mismo sólo pertenecen al cadáver. Afirmar que el proceso histórico es un proceso dialéctico ha de implicar, por tanto, concebirlo como un proceso vivo.

También en los animales ovíparos, el huevo del que emerge la cría muestra un cambio cualitativo comparable a un salto, al igual que en los mamíferos la diferencia que separa el feto del animal recién nacido. El mundo natural es pródigo en ejemplos del tal salto cualitativo aunque exprese una dialéctica muy pobre y defectuosa.

Recordemos el ejemplo que ponía Hegel de la flor convertida en fruto y después en semilla. O la imagen más sencilla de la que gustaba Engels, del agua que a no más calentarla por encima de cierto grado se convierte en vapor y si se enfría se hace hielo. Es decir, lo que hay que captar es la idea de la discontinuidad o ruptura ligada a la idea de la continuidad. En un momento de esta secuencia ya no tenemos agua un poco más caliente sino que el líquido se nos ha convertido en gas $\mathrm{O}$, a la inversa, si la enfriamos gradualmente se vuelve sólido. Parecidamente con los demás ejemplos. Un cambio que es meramente cuantitativo, en la medida que tiene un efecto acumulativo, se convierte en un cambio cualitativo. El agua sigue siendo agua, pero no es la misma idéntica agua cuando la encontramos en estado líquido, sólido o gaseoso.

El agua del mar es lo blando por excelencia, no obstante esa misma agua puede quebrar la dureza del acero y hundir un barco como el Titanic, tal como la industria cinematográfica tuvo a bien recordarnos años atrás. La misma agua que dócilmente adopta la forma del recipiente, estallará y hará añicos la olla de presión si la dejamos calentar demasiado. Así como hablamos en imágenes cuando nos referimos a una insurrección como "explosión social", también lo hacemos al Ilamar salto cualitativo al momento dialéctico de ruptura y discontinuidad.

Pero los ejemplos de la naturaleza, aunque ayudan a entender, no expresan un auténtico movimiento dialéctico, en contra de lo que pensaba el amigo y compañero de Marx. Porque lo central de la dialéctica no es el salto cualitativo sino la relación que se establece en la oposición de contrarios. Ésta no está plenamente presente en el mundo de la naturaleza sino en el mundo de la historia, en el mundo de la sociedad humana. En contestación a lo que opina el colega y a su burla con lo de las ranas, tenemos que repetir con Galileo: "Y sin embargo se mueve". No porque defendamos que la dialéctica lo explica todo en el terreno de la historia; métodos diferentes dan interpretaciones 
complementarias. Sino porque estamos convencidos de que ofrece explicación en un nivel de lectura que ningún otro método de análisis puede hacerlo. Otros enfoques son incapaces de dar respuesta a ciertos problemas. Es más, ni siquiera pueden plantear las preguntas.

Coincidimos por tanto, no solamente con los distintos autores de ascendencia hegeliana así como de las diferentes corrientes marxistas, sino también con pensadores que desde otras influencias teóricas reconocen en la dialéctica una forma de pensamiento válida y un legítimo método de análisis. Entre los intelectuales que están en esta postura se destaca el caso de Ellacuría. A pesar de verse a sí mismo como discípulo y entusiasta divulgador de la obra filosófica de Zubiri, quien definía que la realidad es dinámica pero no es en sí dialéctica, Ellacuría planteó que aunque la realidad no sea dialéctica en cambio sí lo es la realidad histórica. Su afirmación lo distancia de su maestro puesto que también defendía que la realidad histórica debe tomarse como el auténtico objeto de la filosofía dado que es en ella "donde la realidad puede dar más de sí, donde la realidad es más suya y donde es más abierta". ${ }^{1}$

En su obra, en especial en sus escritos de análisis político y de coyuntura, Ellacuría utilizó muy frecuentemente el método dialéctico de análisis y su redacción está plena de imágenes y expresiones típicamente dialécticas. Deseamos enmarcar el modesto esfuerzo de análisis que aquí se emprende en estas tradiciones intelectuales. No sólo eso: quisiéramos contribuir a revitalizar la dialéctica como un modo científico y revolucionario del pensar.

Si es factible analizar la historia mediante el método dialéctico es porque el material al que dicho método se aplica, el proceso histórico, es asimismo de naturaleza dialéctica. Pero esto necesita ser desvelado por el investigador mediante un enfoque apropiado. Las preguntas que éste formule a su objeto de estudio pueden ser determinantes. El proceso abre sus secretos a quien lo enfoca con una mirada adecuada. En nuestro caso, la primera pregunta que cabe formular frente al proceso es: ¿cómo de la guerra pudo surgir la paz? Es decir, ¿cómo la paz se transformó en su contrario dialécti$\mathrm{CO}$, en la no-guerra? La interrogante central de nuestro estudio, lleva implícita otra pregunta paralela y anterior: ¿cómo de la paz de los setenta brotó la guerra de los ochenta?

Esta última es una cuestión aparentemente más sencilla, en la medida que está más a la vista y no requiere de una concepción dialéctica de la historia para visualizarla y plantearla. Es claro que la paz se transformó en guerra debido a sus propias contradicciones. Aceptar esto es ya plantear, aunque sea de manera inadvertida, la existencia 
de una dialéctica en el proceso histórico. Se deberá también asumir lo que está implícito en nuestra hipótesis teórica: que las dinámicas que hicieron posible la paz surgieron desde la propia lógica de la guerra, que la pacificación no fue "impuesta" exteriormente al proceso, sino que fue resultado lógico de su propio desarrollo.

\section{El proceso histórico salvadoreño como proceso nacional}

Si el proceso histórico es un proceso dialéctico y además lo es en sentido estricto, eso significa que ha de ser un proceso de carácter interno. Es decir, la verdadera dialéctica no está en la simple existencia del cambio, sino en el hecho de que la transformación se da, no por factores exteriores, sino por un proceso interno. Será fruto de su desarrollo mismo y de la propia lógica de su movimiento. Este movimiento que deriva de su esencia es, por definición, un auto-movimiento.

Hegel explicaba que cuando una planta es comida por una vaca, ésta se constituye entonces en el accidente de la planta. Pero si no es devorada $-y$ suponiendo que concurran otros aspectos accidentales como lo favorable del terreno y del clima- la planta seguirá su desarrollo por sí misma, dando en su momento las semillas correspondientes para su reproducción y supervivencia como especie. Ahí no manda la casualidad sino la necesidad. El proceso tiende a completarse necesariamente.

La planta de cebada dará granos de cebada y de la planta de frijol cosecharemos frijoles. $\mathrm{Ni}$ la una ni la otra se van a confundir en esto. Nunca obtendremos frijoles de la cebada, ni granos de cebada del frijolar. Es resultado de un proceso interno, de algo que ya estaba presente en la semilla, de un código genético concreto que domina el interior del viviente. Por tanto, la verdadera dialéctica no se establece entre la vaca y la planta, sino entre la planta y ella misma, como un proceso de desarrollo internamente determinado.

El viviente posee su propia dialéctica, su propio movimiento interno, del que carece la simple cosa. Expresa la superioridad de la materia orgánica sobre la materia inorgánica. El organismo se determina a sí mismo mientras lo inorgánico es determinado desde su exterioridad. Tampoco la piedra permanece inalterable. Sufre mutaciones. Es erosionada por el aire y el agua, objeto de reacciones químicas y de procesos físicos que la transforman. Pero todo ese movimiento es exterior a la piedra misma, "le ocurre" todo eso como por accidente y no por una necesidad interna que brote de sí misma.

Hechas las anteriores consideraciones pasemos a nuestro tema: 
¿cómo habremos de considerar al proceso histórico?, ¿como algo inorgánico, mineral, muerto?, ¿o como algo vivo, orgánico, capaz de automovimiento? Pareciera que algunos contemplan el proceso histórico salvadoreño como algo sin vida, inerte, carente de esa capacidad de autodeterminación propia de los procesos orgánicos. O tienden a verlo como aquella planta a punto de ser devorada por la vaca. El proceso salvadoreño sería una víctima de "accidentes", de intromisiones externas que lo habrían estado determinando en cada momento. La vaca puede representar, bien a Estados Unidos, bien a la Unión Soviética, Cuba y Nicaragua, según la visión ideológica de cada cual. Pero todas éstas parten de la misma óptica: un "gran animal" viene desde fuera y hace que "le ocurran cosas" a nuestro pequeño e inerme país. Zarandean nuestra planta y propician entonces la guerra "fratricida", inexplicable -según estas versiones- si no es por la injerencia externa.

Mas después deciden no devorarnos, sino dejarnos tranquilamente en nuestra maceta y ayudarnos a seguir creciendo. Imponen entonces la paz. Son agentes externos, que unas veces se comportan con nosotros como demonios y otras por el contrario como dioses bondadosos, a los que debemos agradecer por nuestra afortunada historia, la cual gracias a ellos cuenta así con su final feliz. Bien sea en forma de cuento para niños, bien sea como apéndice de algún estudio de política internacional, por este camino nos quedamos sin historia. Es decir, sin historia propia.

Quienes defendemos que El Salvador tiene historia y que debemos conocerla, analizarla y comprenderla, estamos obligados a romper con aquellas concepciones que -a veces de manera bienintencionada, tal vez con fines de denuncia o por un confuso nacionalismo o antiimperialismo- en realidad sitúan las claves para la comprensión de nuestro proceso allende las fronteras.

Habría que buscar en Moscú o en Washington, en La Habana o en Managua, o en ciertas capitales europeas, las razones explicativas de nuestro proceso. Defender que tiene sentido analizar el proceso salvadoreño como proceso interno, que es ante todo nacional, no significa despreciar las dimensiones internacionales del mismo o la importancia del papel que determinadas potencias jugaron en él. Pero la diferencia es esencial y no mera cuestión de énfasis o acentos: ¿estuvo el proceso determinado por factores externos o en lo fundamental se determinó internamente?

Desde el punto de vista teórico la cuestión queda contestada si se acepta el punto de vista de la dialéctica. Desde el punto de vista práctico la respuesta la dará nuestro análisis: si logra exponer el proceso 
histórico sin recurrir a los agentes externos para una explicación fehaciente.

Algunos colegas han enfocado esta cuestión mediante un análisis más fino y lleno de matices. Héctor Dada planteaba que algunos agentes externos se habrían convertido en actores internos. ${ }^{2}$ Se refería en concreto al papel de Estados Unidos. Habría habido un proceso de internalización que supondría la inversión dialéctica respecto al proceso de internacionalizacón que venía operando sobre el conflicto salvadoreño.

Sigue a eso una fuerte crítica al gran involucramiento norteamericano en apoyo al bando gubernamental. Es interesante $y$ sin duda la tesis contiene dosis de verdad. Pero, en mi opinión, hay exageración en el planteamiento, el cual no puede tomarse al pie de la letra, pues deja demasiadas cosas en el aire. Si Estados Unidos pasó a ser un actor interno la tesis no contradice la nuestra de que el proceso debe ser tratado como proceso nacional, o sea, determinado internamente. Pero sí la contradice en la medida que Estados Unidos siga siendo considerado como lo que es, una potencia extranjera.

Pero el problema no es tanto esa ambigüedad. Lo grave es que no hay correspondencia con los hechos. Estados Unidos nunca llegó al extremo de invadir el país. En la negociación no participó como actor interno, integrándose a uno de los bandos, sino como uno de los países garantes de la negociación y de sus resultados. Tampoco el gobierno estadounidense fue quien determinó el fin del conflicto, al igual que no había determinado su inicio. $Y$ desde luego, mucho menos pudo determinar su evolución, siendo que el desenlace de la guerra resultó otra cosa muy diferente que la victoria militar sobre la insurgencia, que con tanto ahínco había venido buscando.

No se trata de subvalorar la importancia de la injerencia norteamericana, la cantidad de medios que puso a disposición del gobierno o los miles de millones de dólares que volcó en el conflicto salvadoreño. La participación de Estados Unidos resultó decisiva en muchos momentos y situaciones. Pero decisivo no significa determinante. Sería exagerado y erróneo considerar que el proceso vino siendo determinado por Estados Unidos y que es en la política norteamericana y su evolución donde están las claves para su interpretación. Más bien la relación debe establecerse a la inversa. Será desde la comprensión a cabalidad del proceso interno salvadoreño que podrá entenderse la política estadounidense hacia El Salvador, sus variantes y sus virajes. Estados Unidos influye desde fuera sobre el proceso, pero también es influido 
por él. Participa desde dentro en forma muy activa, prácticamente como un actor más, pero justo por eso el proceso termina imponiéndosele, al igual que al resto de actores.

\section{Elproceso histórico como proceso fáctico}

No debe perderse de vista que el proceso histórico, en tanto que real, se compone de una serie de acontecimientos o hechos históricos. El análisis del proceso debe ser, ante todo, el análisis de los hechos. Si la subjetividad de una hipótesis de interpretación nos desvía de la objetividad fáctica del proceso, andamos mal. Sin embargo, el lugar central que ocupan los hechos no debe inhibirnos de otras posibles perspectivas, que no por audaces deben ser excluidas.

A la sombra de lo que verdaderamente ocurrió se sitúa lo que, de manera igualmente real, no aconteció. Es otra presentación de la verdad: lo que de veras no pasó. Al mundo de los hechos, como la imagen invertida en un espejo, corresponde el mundo de los nohechos. No cualquier evento que caprichosamente queramos pensar, sino aquellos acontecimientos que en su momento tuvieron visos de posibilidad. Si el tiempo presente y el futuro los definimos como campo de posibilidades reales, debe aparecernos la posibilidad también en el tiempo pasado. Porque ese pasado había sido, en momentos anteriores, futuro y más tarde fue presente.
La posibilidad debe tomarse en cuenta en nuestra valoración del pasado. La que fue posibilidad real, aunque no haya sido concretada históricamente, no debe desaparecer de nuestra consideración. Si lo hiciera se cerraría la posibilidad de abarcar la perspectiva que los seres humanos de la época tuvieron cuando el pasado era presente, cuando lo que hoy es historia estaba haciéndose. Para recuperarla debemos afirmar los no-hechos en su carácter de realidad. El nohecho es la posibilidad del pasado, es la que fue posibilidad real en un momento del pasado. Lo fáctico del proceso histórico abarca tanto el campo de los hechos como el de los no-hechos.

Complementando la lógica de los hechos aparece la de los nohechos, o sea, lo que aconteció verdaderamente, respaldado por lo que realmente no ocurrió. Es más que una diferencia semántica, es más que un decir en negativo lo mismo pero a la inversa que podemos decir en positivo. Así por ejemplo, no se dio una insurrección popular que permitiera la toma del poder en enero de 1981, cuando la guerrilla lanzó su "ofensiva final". Aunque eso fue posible y fue vivido como 
posibilidad real en su momento histórico. A tal punto que uno de los miembros de la Junta gobernante apareció en el aeropuerto de San José, Costa Rica, con toda la familia y cargando siete maletas.

Lo mismo en positivo es afirmar que con dicha operación militar del FMLN dio comienzo formalmente la guerra civil en El Salvador. Lo que se dio y lo que no se dio aparecen como visiones complementarias, la ojeada sobre los no-hechos ayuda a visualizar los hechos reales del proceso. En otros casos, la diferencia de enfoque de esta doble mirada, a la luz de los hechos y a la sombra de los no-hechos, abre para el análisis perspectivas más diversas y mucho más sugerentes.

Es el caso de la política estadounidense hacia El Salvador a lo largo de toda la década de los años ochenta. Se abrió al respecto una polémica que tiene que ver con una doble lectura de dicha política. Enjuiciándola desde sus metas proclamadas varios congresistas demócratas la criticaron duramente. La Administración republicana no había obtenido ninguna. Esta política ha fracasado en los hechos, aseguraban. Y tenían razón. Estados Unidos no había derrotado a la guerrilla, ni reducido su influencia, no había logrado una mejora sustancial en la situación de los derechos humanos, tampoco había conseguido erradicar la corrupción e ineficiencia del Estado salvado- reño, la política de reformas que había diseñado e impulsado estaba en bancarrota, etc.

La respuesta republicana centraba su propio diagnóstico en los objetivos propuestos. Desde ellos, afirmaban, el balance era positivo. Estados Unidos había logrado conjurar la posible derrota de la Fuerza Armada y la toma del poder por parte de la guerrilla, también pudo impedir que un golpe de Estado diera al traste con su estrategia contrainsurgente de reformas y democratización, consiguió evitar el colapso de la economía, tuvo éxito en impedir que otro régimen con posturas anti-norteamericanas y simpatías pro-soviéticas o pro-cubanas se instalara en América Central.

Ellos también tenían razón. Desde la perspectiva de lo que lograron evitar, es decir, de lo que no ocurrió. Obsérvese que la suya es una enumeración de no-hechos, pues los objetivos estaban formulados en negativo, frente al balance de hechos que se hace al examinar las metas, definidas en positivo. Estados Unidos logró sus objetivos, a pesar de haber fracasado en las metas trazadas. En eso reside todo el misterio de ese debate interminable: en la dialéctica de los hechos y los no-hechos.

Otro ejemplo: en el arranque del conflicto salvadoreño no fue Reagan, el recién electo y archiconservador Presidente republica- 
no, quien realizó el viraje desde la política de permisividad que había exhibido su antecesor, el demócrata Carter, tolerante para con la victoriosa revolución sandinista. El cambio radical de la política norteamericana hacia Centroamérica lo inició el propio Carter, cuando en noviembre de 1980 rehusó dialogar con la insurgencia salvadoreña y en enero siguiente, ante el anuncio de la Ilamada "ofensiva final" del FMLN, envió ayuda militar de emergencia al gobierno salvadoreño. La tesis que defiende el papel determinante de Estados Unidos queda cuestionada por este no-hecho: no fue la llegada de Reagan lo determinante, no fue el cambio en la Administración norteamericana. Inversamente, fue el cambio en el proceso salvadoreño ( $y$ en el nicaragüense) lo determinante para el viraje en la política de Washington.

Parecidamente al momento de desencadenarse la negociación. El cambio de política en Washington parecería lógico si se hubiera dado a partir de la llegada del demócrata Clinton, tras doce años de dominio republicano. Pero éste es también un no-hecho: fue el republicano Bush, quien fuera Vicepresidente con Reagan y ya en la Presidencia fiel continuador de la política de éste, el que realizó el viraje para permitir y, más tarde, apoyar decididamente la negociación y la salida política. Lo cual no puede atribuirse a que repentinamente una voluntad política no-interven- cionista haya inspirado a la gran potencia norteamericana.

A la par de los no-hechos debemos situar los hechos: Estados Unidos invadió Panamá en diciembre de 1989, poco después de terminada en El Salvador la ofensiva llamada "hasta el tope". No obstante utilizar medios militares para apresar al general Noriega y disolver la Fuerza Armada de Panamá, el gobierno de Bush en lugar de intervenir militarmente en el conflicto salvadoreño permitió la apertura de la negociación y un año más tarde la acuerpó decididamente. Todo lo cual habla a favor de nuestra tesis de que es en el proceso interno salvadoreño donde están las claves para la comprensión y el análisis de nuestra historia.

Todo esto no nos lleva a ignorar los aspectos internacionales, sino a ubicar éstos en el contexto que verdaderamente les corresponde. Lo que pasa en el mundo enmarca e influye. Pero no llega a determinar los procesos internos de cada país. Ni siquiera algo tan estruendoso como la caída del muro de Berlín, que más de alguno, por ignorancia o por malicia, pretende que explica la aceptación por la guerrilla del mecanismo negociador. La cronología y los datos desmienten estas elucubraciones. La caída del muro se dio dos días antes del inicio de una ofensiva que el FMLN venía preparando 
desde hacía más de dos años y que contemplaba en su planificación la apertura de la negociación como su "objetivo mínimo". Explicaciones simplistas, peor si ideologiza- das o con fines de propaganda, no sirven para clarificar la complejidad de un proceso como el de El Salvador durante estas tres décadas que aquí analizamos.

\section{Factores estructurales y superestructurales}

¿Por qué Estados Unidos invadió Panamá y no invadió El Salvador? Es una cuestión que acabamos de abordar y no insistiremos más en ello. Formulamos la pregunta porque incita a otras similares, que también combinan lo que pasó con lo que no ocurrió. ¿Por qué durante los años ochenta hubo guerra en El Salvador, Nicaragua y Guatemala pero en cambio no la hubo en Honduras ni en Costa Rica? ¿Por qué en Nicaragua hubo revolución triunfante, mientras en El Salvador no se pasó de un empate y en Guatemala más bien se inclinó la situación bélica a favor del ejército?

Agreguemos otras preguntas más a estas primeras. ¿Por qué mientras en Nicaragua la revolución alcanzó la victoria de manera bastante rápida, tras año y medio de ofensiva sandinista, por el contrario en El Salvador no bastaron doce años de intensa guerra para posibilitarle a la guerrilla la toma del poder? ¿Y en Guatemala? ¿Por qué treinta años de lucha guerrillera no fueron ahí suficientes para alcanzar una negociación ventajosa como la salvadoreña, con mejores acuerdos y mayores garantías de su cumplimiento?
Llama la atención que en una región relativamente homogénea como la centroamericana cada proceso nacional se presente de tal manera diferenciado. Podría decirse que, a grandes rasgos, la estructura económica y la problemática social son semejantes en toda la región. Tan sólo Costa Rica constituye una excepción, por su abundante clase media, con su mediana propiedad bastante extendida en el campo, sus derechos laborales para los trabajadores urbanos, con contradicciones sociales menos agudas, con su relativa estabilidad política, sus tradiciones democráticas y la ausencia de un ejército nacional. Desde los diferentes factores estructurales parece lógico que hallemos en Costa Rica una evolución histórica diferente a la del resto de Centroamérica. Pero este mismo argumento debiera valer a la inversa. En los otros cuatro países cabría esperar un proceso histórico paralelo, determinado por una similar crisis estructural.

¿Por qué hubo guerra civil en El Salvador y no la hubo en Honduras? La interrogante constituía el título de un artículo que publicó Rafael Pleitez. ${ }^{3}$ Una problemática tal vez algo 
extraña para el campo de especialidad de un economista. De hecho, el autor apenas conseguía mantenerse en el terreno de la economía - "la desigualdad de la distribución de la tierra como la variable clave" e incursionaba en otras áreas: el contexto político, la represión de las organizaciones campesinas, la reforma agraria, la estructura estatal, el papel de la religión, la conciencia de la injusticia social, etc. Aparte de que aceptemos o no su propuesta de crear un "Índice de Inestabilidad Social" y de lo discutible que pueda resultar su intento por cuantificar los componentes que configuran una situación revolucionaria o insurreccional, queda bastante clara la imposibilidad -inclusive para un economista- de reducirse a meras consideraciones económicas para la comprensión de procesos históricos complejos que entrañan diversidad de variables.

El carácter nacional de los procesos, que ya habíamos antes dejado establecido, nos conduce ahora a reexaminar el papel de los factores estructurales, entendiendo por tales aquellos referidos a la estructura económica. $Y$ es que resulta que lo menos marxista del marxismo -al menos en comparación con los planteamientos del propio Marx- ha sido lo que con mayor fuerza se ha popularizado: el economicismo. La tendencia a considerar la "determinación económica" como la clave explicativa de cualquier fenómeno histórico o político, ha rebasado los círculos marxistas y es defendida por investigadores de las escuelas teóricas más diversas. Incluso ha Ilegado a ser común el que al referirse a "factores estructurales" todo el mundo entienda "factores económicos". No debiera ser así, pues también tienen naturaleza estructural aspectos sociales como la estructuración de clases, aspectos políticos como el sistema y régimen políticos, o aspectos ideológicos como las creencias religiosas o las corrientes filosófico-políticas. Pero nos ha quedado esa herencia de la conocida tesis marxiana de que lo determinante en última instancia es la economía. Lo de "en última instancia" casi nadie lo toma en cuenta y posiblemente no fue suficientemente subrayado por Marx y Engels, de modo que hoy día es frecuente que tanto la izquierda marxista como la derecha anti-marxista coincidan en la creencia de que es la estructura económica (o la "crisis estructural") la determinante que explica todo el acontecer histórico.

¿No se nos repite hasta la saciedad que la causa de la conflictividad en los países centroamericanos está en la llamada crisis estructural? Pero si eso fuera así, ¿cómo explicar las grandes diferencias entre los procesos históricos de países que comparten parecidos problemas económicos, que están todos ellos sumidos en una especie de "crisis estructural permanente" y bajo similares condiciones de explosividad social? Sin duda la crisis estructural 
existe y explica cosas simples como el hecho de que haya sido la región centroamericana y no, por ejemplo, la zona de los países escandinavos la que se sumió en la grave perturbación social, política y militar de los años ochenta. Pero no es convincente cuando se pretende reducir a esa única causal explicativa la totalidad del fenómeno y el detalle de su compleja evolución.

Un segundo problema aparece si nos quedamos con el planteamiento de que es la "crisis estructural" la causa determinante. Hay un relativo consenso en que la solución política negociada no vino a resolver los problemas económicos y sociales que abatían a El Salvador. Si la negociación no resolvió la crisis estructural que, se nos repite, había ocasionado la guerra: ¿cuál es la situación y perspectiva actuales? Se solventó la guerra pero no se solucionó su causa principal... ¿Se encamina entonces el país de regreso al conflicto? ¿Estamos en puertas de una nueva guerra, diferente a la anterior, pero guerra al fin y al cabo? Nuevamente observamos cómo las respuestas sencillas lejos de resolver nos abocan a nuevos y graves problemas de interpretación.

No podemos eludir la complejidad del proceso histórico real. La crisis nacional en que entró El Salvador tiene diversos componentes a la base de los cuales en última instancia se encuentra la crisis del modelo económico que venía arrastrándose por varias décadas. ¡Pero las instancias intermedias cuentan y mucho! La mediación de los niveles políticos, sociales e ideológicos es decisiva para configurar la agudización de la crisis nacional y la radicalidad de las salidas posibles a la misma. El análisis debe incorporar instancias intermedias y no solamente la última, si de verdad va a intentar responder al desarrollo concreto del proceso histórico.

Por otra parte, no sirve esa visión que separa causas de efectos. Entre los efectos de la guerra civil está el haber alterado la estructura económica, su funcionamiento, el modelo económico sobre el que giraba la economía salvadoreña. Hoy seguimos en crisis pero no se advierte que la crisis es otra, porque también las bases económicas de la acumulación y del modelo han cambiado. No como fruto de algún plan o por la aplicación exitosa de alguna política, sino como consecuencia no buscada e inadvertida del mismo proceso. A lo que habrá que agregar los efectos mentales, ideológicos, de ese cambio. 


\section{Factor determinante y factor dominante}

¡No quedarse en el nivel de la determinación "en última instancia" y pasar a las otras intermedias, a la determinación en primera y en segunda instancia! Es la única vía para no quedar reducidos a una visión tan general que permanecerían borrosas las diferencias y se perdería toda la riqueza de los detalles. Eso no significa rebatir a Marx, ni negar las verdades que él descubrió. Lo económico resulta determinante en la sociedad y en la historia. Está demostrado. Pero eso no lo es todo, ni puede explicarlo todo. Puede bastar para exponer a grandes líneas la evolución general de la humanidad o para caracterizar los diferentes modos de producción, pero resulta a todas luces insuficiente para períodos históricos cortos, de unas décadas o unos pocos años. Pretender, con tales herramientas teóricas, analizar un breve segmento histórico en un país concreto como el nuestro debería verse igual de ridículo o de monstruoso que si el dentista se nos acercara con una llave inglesa en una mano y un martillo saca-clavos en la otra. El instrumento debe corresponder a su finalidad. Las tenazas pueden ser muy útiles, pero para ciertos menesteres necesitamos de unas pinzas.

Con el tiempo ocurre algo semejante al espacio. Para estudiar estrellas y galaxias están los telescopios. Mas para espacios diminutos utilizamos una lupa. Pero si estamos en dimensiones minúsculas necesitaremos un microscopio. Aunque sirven para propósitos distintos, el telescopio y el microscopio están construidos sobre los mismos principios. Un similar juego de lentes, pero en relación invertida, ocasionará efectos contrarios. Es lo que comprobamos al jugar con unos prismáticos: mirando por el extremo opuesto, en lugar de agrandar, el aparato empequeñece lo que enfocamos.

Para las dimensiones temporales de nuestro objeto de estudio precisamos asimismo unas herramientas adecuadas a su relativa pequeñez. Los telescopios y catalejos que utilizó Marx dudosamente mejorarán nuestra visión de los treinta años de proceso salvadoreño que constituyen nuestro problema. Debemos fabricarnos nuestro propio instrumental a fin de tener claridad de eso que a simple vista se mira borroso. Pero en este empeño no partimos de nada. Contamos con los lentes y con los principios que descubrieron los grandes maestros del pasado y que aplicaron con otros propósitos. Lo que debemos es atinarle a combinar unos con otros en una manera que resulte conveniente a nuestra finalidad.

Revisemos primero en qué puede ayudarnos Marx, ya que venimos ocupándonos de él. En su mirada a las grandes etapas de la historia 
europea Marx constató una variación de importancia: mientras en la "sociedad moderna" (capitalista) lo económico además de determinante es también dominante, no había sido de igual manera en anteriores modos de producción. En la sociedad medieval lo dominante era la religión, mientras en la sociedad esclavista la política dominaba. No coincidían el factor dominante y el factor determinante. Sólo en el capitalismo se da su coincidencia. Por eso mismo, concluía Marx, es que únicamente en la sociedad moderna puede concebirse que es la economía la determinante, tanto en ésta como en sociedades anteriores, donde la mediación de lo político o de lo religioso impedía a los hombres de la época captar la determinación económica. $\mathrm{Ni}$ siquiera tenían una concepción de la economía como una esfera especial y autónoma de la actividad. Carecían del concepto que hoy tenemos, la palabra tenía un significado distinto al que hoy le damos al decir "economía".

Veamos con más detalle la concepción y metodología utilizadas por Marx. En primer lugar hagámonos la pregunta ¿qué determina que en un tipo de sociedad sea en concreto ése y no otro el factor dominante? O sea, ¿por qué la política en el modo de producción esclavista, la religión en el feudal y la economía en el capitalista? Lo que determina cuál va a ser el factor dominante es siempre, para
Marx, la economía. En su explicación son las características de la infraestructura económica, de su modo de producción principal y en especial de las relaciones sociales de producción, las que van a determinar el que en la superestructura político-ideológica predomine uno u otro componente.

Son las relaciones esclavistas la clave para entender un mundo antiguo donde los seres humanos quedan fatalmente divididos en hombres libres y esclavos. La defensa de la libertad va a depender de la fortaleza del poder estatal y por tanto las preocupaciones giran en torno a la política. Se crean firmes instituciones como el derecho de ciudadanía y la democracia. En cambio, la sociedad feudal arranca de la descomposición de aquel mundo, junto con la del imperio romano. Ahora los hombres se dividen en señores y siervos. Ya no son propiedad de otro pero, sujetos a la servidumbre, están obligados al servicio a su señor y al trabajo gratuito. La religión impregna la sociedad medieval, cuyo orden desigual queda compensado por una igualdad en "el más allá", pues todos somos "siervos de Dios", El es "nuestro Señor". En contraste, el capitalismo va a liberar a las masas campesinas de la servidumbre, de esa sujeción jurídico-política, y proclamará la igualdad de derechos. Las relaciones de producción, basadas en la libre contratación y en el trabajo asalariado, convierten en mercan- 
cía todos los bienes, incluidos el trabajador y su producto. Rigen el mercado y sus leyes económicas. El interés y el cálculo económicos "al desnudo" son lo que dominan. Termina el papel dominante de la religión y asciende el de la economía.

La lectura usual de este análisis es que lo económico es siempre determinante en cada sociedad. Pero no es la única. También podemos interpretarlo en la forma siguiente: hay una relación entre el factor determinante y el factor dominante, por la cual el primero determina al segundo. Esta última es la lectura que nos interesa retener y a la que vamos a regresar más adelante.

Segunda cuestión: ¿cómo domina el factor dominante?, ¿cómo ejerce su dominación? y ¿a quién domina? Domina otras esferas de la vida social, otros conjuntos de relaciones. Lo hace básicamente en el mundo de las ideas, de las concepciones, actitudes, aspiraciones, valores y prejuicios. Es decir, el factor dominante lo es de la conciencia colectiva. Pero a través de ella moldea los diferentes niveles de la vida en sociedad: en la familia, en el trabajo, en la escuela, en la comunidad, etc. Lo hace determinando desde una primera instancia, en forma directa, aqueIlo que el factor determinante sólo en última instancia determina. Es decir, pese a que nuestro punto de partida ha sido la distinción entre los dos factores, dominante y determinante, terminamos concluyendo que ambos vienen a ser lo mismo: capacidad de determinación, en un caso en primera instancia y en el otro de una forma indirecta, en una instancia posterior.

Un tercer aspecto: ¿en qué consisten, tanto el factor determinante como el dominante? Ya lo hemos venido planteando, pero importa dejarlo subrayado: son distintas esferas de la actividad social, niveles diferenciados de la acción humana en sociedad, campos de relaciones sociales. El término es amplio. No ciertas prácticas sociales concretas, sino el conjunto de todas ellas en el nivel correspondiente. Permite ser expresado en su forma neutra: lo político, lo religioso, lo económico. También esto queremos retenerlo.

\section{Espíritu de la época y espíritu de un pueblo}

No solamente existe la conciencia individual, de cada persona humana, también es real la existencia de una conciencia colectiva. Ésta corresponde a los elementos comunes de todas las conciencias individuales en un conglomerado social.
El ser humano nace y se desarrolla en el seno de una colectividad y no puede escapar de esta determinación que lo constituye como ser social. El propio Marx, pese a su reticencia para aceptar que las ideas gocen de una autonomía pro- 
pia, reconocía la existencia de los fenómenos de conciencia colectiva, tanto bajo la forma de "conciencia de clase" como en la modalidad de superestructura ideológica y cultural correspondiente a grandes épocas de la historia, tal como acabamos de comentar. El hombre pertenece a su época, "cada hombre es hijo de su tiempo", afirmaba Hegel. Pretender escapar a esta determinación fuera "tan absurdo como querer saltar sobre la propia sombra". "Desprenderse de su época es para el ser humano tan imposible como tratar de desprenderse de la propia piel".

El mismo idealismo filosófico de Hegel le llevó a poner mucha atención a los aspectos psicológicos, culturales e ideológicos. Mientras a Marx le bastó comparar esclavismo y feudalismo, en contraste con el capitalismo, Hegel en cambio señalaba varias etapas en la evolución de la conciencia colectiva en Occidente. Para la Grecia clásica refería tres formas de conciencia sucesivas: la épica, la trágica y la cómica. Cada una correspondía a momentos del desarrollo de la literatura y el teatro: la épica, la tragedia y la comedia griegas. La primera se refiere a los tiempos homéricos, del asentamiento helénico en el territorio y de la primitiva monarquía. Dioses, héroes y hombres se entremezclan en la acción y el triunfo depende de su alianza. La conciencia trágica se forma desde la instauración de la democracia en Atenas, sus contradicciones y su fortalecimiento. Los hombres ya no dependen tanto de los dioses, por cuanto ahora se gobiernan a sí mismos, pero la acción descansa en los héroes, los cuales sucumben ante la fuerza del destino. El uso de máscaras despersonaliza a los personajes, mientras la presencia del coro enfatiza el fondo colectivo del protagonismo. La conciencia cómica o "conciencia feliz" refleja la libertad de un pueblo capaz de reírse de sí mismo, que elige a sus gobernantes y se da sus propias leyes. Pero hay una contradicción entre el mundo de lo público y el de lo privado, entre la ley humana y la ley divina, tal como se refleja en la obra "Antígona". El mundo griego sucumbe, según Hegel, al no poder resolverla.

El mundo romano abre el espacio para lo individual. Se desarrollan la propiedad privada y el derecho, las grandes obras de infraestructura y una moneda única. La región alrededor del mar Mediterráneo resulta unificada por este nuevo poder militar y político, que absorbe pueblos y culturas mediante el sistema de la ciudadanía romana, la unificación lingüística y la tolerancia en los ámbitos religioso y cultural. Las nuevas figuras de conciencia colectiva que le corresponden tienen ahora que ver, para Hegel, con la filosofía: la conciencia escéptica y la estoica. Viene después, en contraposición con la que culminaba el mundo ateniense, la conciencia infeliz, denominada 
también conciencia escindida o desgarrada. Es la que corresponde a la nueva religión que se ha vuelto oficial en el imperio, el cristianismo. Se entra a la Edad Media de la mano de esa conciencia desgraciada, que ha hecho la separación entre cielo y tierra, que sitúa el ideal en el más allá y lo pierde en el más acá. De ahí el desgarramiento, porque el ideal se vuelve inalcanzable en esta vida y no queda sino la resignación. Todo eso va a quedar superado con el Renacimiento, la Ilustración y la revolución francesa. Debían reconciliarse fe y razón, el mundo de la religión y el de la ciencia, los principios cristianos con los ideales políticos de igualdad y libertad.

El "espíritu de la época" ha cambiado a partir del triunfo de la razón, que inspira el resurgir científico y las nuevas corrientes filosóficas, así como de los ideales humanistas que mueven a recuperar la cultura clásica. El acontecimiento histórico que simboliza por excelencia el derrumbe del antiguo régimen es la revolución francesa. Mientras la conciencia helénica tenía a la base un mundo, la conciencia revolucionaria moderna se centra en un principio. Éste es, en la interpretación de Hegel, la libertad absoluta. Pero la historia muestra una dialéctica contradictoria. El racionalismo genera, en la práctica, irracionalidad. El ideal de libertad absoluta lo que provoca es su contrario dialéctico, la dictadura jacobina, el sometimiento absoluto, el terror como política oficial. La libertad en abstracto no trae vida, sino muerte. Además, una muerte fría, racionalizada, "tan carente de sentido como cortar una col", como la acción de la guillotina, que ahoga en sangre las esperanzas populares en la revolución. Tras el desorden, viene el orden que impone Napoleón Bonaparte. Era necesaria la reconstitución del Estado, de sus leyes, su coerción y su poder. Es la conjugación del ideal con lo real. Hegel admira la figura del general y estadista francés, al que dedica en su diario las siguientes líneas: "Hoy vi al espíritu del mundo montado a caballo, pasando revista a sus tropas". ${ }^{4}$ Con Napoleón no se pierde el ideal revolucionario, pero éste se atempera con el realismo de lo concreto.

La libertad no puede ser abstracta; la auténtica libertad de un pueblo consiste en darse a sí mismo leyes justas, racionales, y en el cumplimiento de las mismas. De ahí deduce el filósofo alemán que es el Estado la clave para alcanzar la racionalidad y la libertad en la historia. La esencia del Estado es la "Idea ética", es "la razón que legisla el mundo", es "el paso de Dios por el mundo". El idealismo filosófico llevó a Hegel a un misticismo en sus consideraciones históricas y políticas que provocaron en Marx su violenta crítica. No hay tal Estado espiritualizado, lo que existe es el Estado de clase, al servicio de 
las clases dominantes. Contra todo idealismo "no es la conciencia la que determina la realidad, sino inversamente, es la realidad social la que determina la conciencia. ${ }^{\prime 5}$

Recapitulemos ahora los aportes que nos da Hegel en el tema de la conciencia colectiva. En primer lugar está lo que él Ilama espíritu de la época, caracterizado por diversidad de componentes, entre los que destacan los de índole cultural e ideológica. Incluye, por ejemplo, elementos de literatura, teatro, filosofía, religión, ciencia, política, etc. Pueblos y masas humanas resultan movidos por las diferentes figuras que "el espíritu" adopta en la historia, resultando ser éste el verdadero sujeto de la misma. Pero podemos obviar ese carácter determinante que el filósofo idealista concede al pensamiento y a la conciencia, para quedarnos tan sólo con sus hallazgos teóricos e históricos. La época caracterizada por una forma de conciencia específica, por un "espíritu" que expresa una determinada sensibilidad, actitud, visión, esperanza y convicción.

En segundo término, cada pueblo posee sus propias características, su idiosincrasia, sus modos de reaccionar y comportarse. Es un terreno de la psicología colectiva. Hegel vio cómo Francia había desarrollado el racionalismo filosófico, Inglaterra el empirismo y Alemania el idealismo. La historia de la filosofía de su época atravesaba por estos tres países. Lo mismo la historia: el paso del protagonismo griego al romano. "Cada pueblo lleva un fruto a su madurez". El espíritu de un pueblo sintetiza en la idea hegeliana esta doble connotación: carácter y misión histórica. Es otro aporte de Hegel.

\section{El espíritu en la historia y los signos de los tiempos}

El uso de la palabra "espíritu" ha cambiado. Hoy día tiende a ser empleada únicamente en textos religiosos o teologales, o en otro tipo de escritos siempre y cuando la temática sea estrictamente espiritual. Pero tiempos atrás fue común su utilización para referirse a los tópicos más diversos. Así por ejemplo, el famoso libro de Montesquieu, "El espíritu de las leyes". Por cierto, una obra con la que Hegel gustaba de dialogar y con la que tenía mu- chas coincidencias. El prestigioso autor francés no innovó en realidad mayor cosa, puesto que casi todo lo que planteó ya había sido enunciado antes por Locke, inclusive su más famosa teoría, la de los pesos y los contrapesos. Sin embargo tiene un mérito indudable: el de la adaptación. Según su criterio, no era conveniente trasladar sin más las ideas del filósofo inglés al público francés, sino que debía traducirse, no sólo de una lengua a otra, sino 
también el estilo y la argumentación, para conseguir el interés y la comprensión de la clase ilustrada francesa. Su voluminoso libro constituye más que nada un ejercicio de traducción, no tanto idiomática como psicológica, cultural, social y política a las características y la situación de Francia.

Explícitamente defiende Montesquieu que las leyes deben adaptarse y tomar como punto de partida las tradiciones, costumbres, creencias, actitudes, sensibilidad y moral, del pueblo concreto al que vayan destinadas. Dedica muchos capítulos a exponer con minuciosidad las particularidades francesas, en contraste con las británicas. No olvida referirse a la geografía, el clima y otras características naturales. Jamás debe copiarse la legislación de otro país, por buena que pueda parecer, pues no hay leyes buenas y malas sino leyes adecuadas o no. También debe tomarse en cuenta la historia y las condiciones políticas, sociales y económicas. Cada pueblo ha de darse el sistema de leyes que más le convenga y transformarlo cuando las condiciones del país hayan cambiado. Es en todo esto que consiste "el espíritu" de "El espíritu de las leyes", un libro sabio que se sigue leyendo hoy día y que es texto obligado para los estudiantes de derecho.

Recoger "el espíritu" de Montesquieu y adaptarlo a nuestros tiempos implica, entre otras cuestio- nes, una cosa paradójica: renunciar a utilizar la palabra "espíritu" para un menester tan laico y alejado de lo sagrado como puede serlo la comprensión del proceso histórico en lo que de psicología social y conciencia colectiva contiene. Lo cual no impide que revisemos en las concepciones del pasado y en las actuales, los diferentes usos que puedan sernos útiles para aclarar nuestra problemática.

Entre las tradiciones que, al igual que Hegel, defienden la presencia de la espiritualidad en la historia está, naturalmente, la cristiana. No debe olvidarse que el gran pensador alemán estudió teología antes de dedicarse plenamente a la filosofía. Un trasfondo que late en su filosofía de la historia es justamente el tema de la Providencia divina y de la relación entre Dios e historia. Si los acontecimientos de la historia son fruto directo de la voluntad divina, si Dios "hace" la historia, desaparece entonces de golpe la ciencia de la historia pues deja de tener sentido. La teología sustituiría a la historia. Cosa diferente es la discusión sobre la presencia de Dios en la historia y en qué forma se manifiesta. Es, nuevamente, un tema teológico en el que no nos corresponde emitir opinión. Pero mencionarlo sirve para poner de relieve el hecho de que la teología se haya ocupado y siga haciéndolo, de temas relacionados con la problemática histórica. También ésta ha de ser una fuente a 
tomar en cuenta, en especial desde el continente latinoamericano y desde El Salvador, donde los cristianos han jugado un papel muy relevante en la historia a partir de los años sesenta.

En la obra teológica de Ellacuría encontramos, sobre lo que veníamos comentando, la siguiente opinión: "Hay una omnipresencia de Dios en la historia. (...) Puede separarse Dios de la historia, pero no puede separarse de Dios la historia." ${ }^{6}$ Por otra parte, una expresión que con gran frecuencia es utilizada por la teología actual, en especial por la llamada "teología de la liberación", es la de tomar en cuenta los signos de los tiempos. En las palabras de Ellacuría: "la trascendencia histórica cristiana que abarca (...) lo que el Espíritu ha ido creando y manifestando y que es menester descifrar como "signos de los tiempos"." Es tal la importancia que el autor le concede, que ofrece una bibliografía específica y menciona la posibilidad de una "teología de los signos de los tiempos".?

Hay una referencia explícita al concepto cristiano y teológico de la expresión "signos de los tiempos" en un artículo de Jon Sobrino: "...la seriedad con que esta teología [de la liberación] toma los signos de los tiempos, exigencia que el Vaticano II hace a la Iglesia y que la teología de la liberación la aplica también a sí misma en cuanto teología: escrutar los signos de los tiempos es necesario para "hacerse cargo" de la realidad. (...) El Vaticano II, en efecto, entiende por signos de los tiempos, por una parte, "los acontecimientos, exigencias y deseos... el mundo en que vivimos, sus esperanzas, sus aspiraciones y el sesgo dramático que con frecuencia los caracteriza" con lo cual "signo de los tiempos" es un concepto histórico-pastoral (...) Pero no es ésa la única ni la más importante acepción: "El pueblo de Dios ... procura discernir en los acontecimientos, exigencias y deseos, de los cuales participa juntamente con sus contemporáneos, los signos verdaderos de la presencia o de los planes de Dios". Estos signos son históricos, como en la anterior acepción, pero ahora se comprenden sacramentalmente (...) Por eso hablamos ahora de signos de los tiempos en su acepción histórico-teologal." ${ }^{8}$

En resumen, encontramos en estos y otros textos teológicos una comprensión del tiempo histórico en la que se destaca la necesidad de tomar en cuenta, de adaptarse o de actuar, de reaccionar en suma, a las exigencias que lo nuevo y actual en la historia plantea para el cristianismo. Es crucial en ella la idea del cambio, de lo nuevo, del "novum", como decía Ernst Bloch, en la utilización teologal de la expresión signos de los tiempos. Es la necesidad para la religión y para la Iglesia de combinar la tradición y la continuidad con la novedad y la innovación, para justamente permanecer 
"a la altura de los tiempos" y de sus exigencias. Debe repararse que no es casual la palabra signo que se utiliza. Signo no es lo mismo que símbolo ni es sinónimo de señal. Se puntualiza: "nos encontramos con una conexión intrínseca del signo con lo significado; más aún podría entenderse el signo como la unidad del significante y del significado." ${ }^{\prime \prime}$ La precisión es importante y resulta sugerente para nuestra problemática, que no es sino des-cubrir y de-mostrar la significación que el proceso histórico tiene, el significado de los acontecimientos.

\section{La síntesis de lo material y lo espiritual, lo objetivo y lo subjetivo, lo consciente y lo inconsciente}

La ciencia de la historia, en tanto va referida a la historia humana real, no puede prescindir de la espiritualidad. Justamente porque los seres humanos poseemos una dimensión espiritual, que es esencial en nosotros, parte de nuestra naturaleza. Esto es así previamente a cualquier consideración religiosa y al margen de no importa qué sistema de creencias. También el ateo tiene espiritualidad. Se trata de algo que es constitutivo de la persona humana y que no puede obviarse.

El peligro para la construcción de la historia como ciencia está en que esa consideración genere un misticismo interpretativo que la impida, como ocurrió durante siglos de época medieval y que todavía pesaba en la visión del idealismo alemán, inclusive la de Hegel. Pero el riesgo contrario está en eludir lo anterior excluyendo totalmente las dimensiones espirituales. Es un poco lo que le ha pasado a la concepción marxista de la historia, también conocida como "materialismo históri-

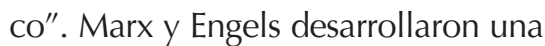
concepción científica de la historia de la humanidad tomando como base la materia y la vida material de los hombres, percibiendo la historia como el reino de la necesidad y tratando de descubrir en él las leyes que lo rigen, las "leyes del desarrollo histórico". Resulta dudoso que lo hayan conseguido. No se puede sin más echar por la borda la parte de realidad humana que está compuesta de esperanzas, de ideales, de ilusiones y creencias, de vida psicológica y espiritual. En realidad, tampoco Marx y Engels lo hicieron del todo, siendo que una de sus preocupaciones centrales era la de cómo ayudar a promover la "conciencia de clase", cómo superar la ideología dominante, dado que en cada sociedad "las ideas dominantes son las ideas de la clase dominante", cómo generar entonces "conciencia política" y "conciencia histórica".

Debe también recordarse que el joven Marx escribió que su filosofía (materialismo dialéctico) se 
convertiría en una fuerza material cuando el proletariado la conociese y la hiciese suya. ${ }^{10}$ Es decir, no hay un abismo que separe lo espiritual de lo material; algo que es de naturaleza espiritual -como la filosofía- puede transformarse en algo material. Obsérvese que, si a la claridad de objetivos y voluntad de lucha de una clase social, el proletariado, Marx le llama "fuerza material" es porque lo usa como sinónimo de "fuerza real". Sin embargo, también debería ser considerada real la "fuerza espiritual". Así como Einstein demostró que la masa y la energía podían convertirse la una en la otra, porque en el fondo son lo mismo y ambas son aspectos de la realidad material, igualmente podría decirse en historia de lo material y lo espiritual, esa forma de energía psicológica y moral. El lenguaje refleja esas equivalencias: la persona "enérgica" o "fuerte de espíritu" frente aquella otra "falta de espíritu" o "desanimada", es decir, con debilidad del ánima, del espíritu, carente de fuerza psicológica. $\mathrm{Si}$ asumimos que la realidad del cosmos está compuesta de materia y energía, si aceptamos la cientificidad de esta afirmación, debemos reconciliar Marx con Einstein y reconocer que la realidad histórica se compone de lo material y lo espiritual. Vamos a necesitar de una categoría teórica que nos represente la síntesis de ambos extremos.

En segundo lugar, dicha categoría deberá ser también síntesis de la objetividad y la subjetividad, tema al que ya hemos hecho referencia anteriormente. También entre una y otra se produce un trasvase, una conexión o equivalencia. En parte, por lo que dijimos antes de que los sujetos son objeto de la historia, mientras el proceso objetivo aparece como el sujeto. También hay otras consideraciones. Por ejemplo, alguien tan poco sospechoso de idealismo como Lenin, consideraba que "el estado de ánimo de las masas" debía ser considerado como parte de los "factores objetivos" para determinar la existencia o no de una situación revolucionaria, siendo que los factores subjetivos de la misma quedaban reducidos a lo concerniente al partido: una concepción programática correcta, una táctica y estrategia adecuadas, acierto en escoger el momento, consignas oportunas, audacia y decisión en los dirigentes, etc. ${ }^{11}$

Algo aparentemente tan subjetivo como "el estado de ánimo" es, no obstante, considerado factor objetivo por parte del dirigente bolchevique. Se muestra ahí lo equiparable de ambos extremos. También es cierta la equivalencia contraria: la pobreza, por ejemplo, que es una cuestión objetiva, no resulta en historia tan decisiva como la conciencia que de la misma tenga el pobre. Lo que tiene repercusiones históricas no es tanto la pobreza sino cómo ella sea vivida, justificada, aceptada o rechazada. Cómo el factor objetivo opera en la forma 
de factor subjetivo, eso es lo que resulta de veras importante históricamente.

Al referirnos a la objetividad y la subjetividad hay que partir de su complejidad, la cual se refleja en su propio desdoblamiento. La subjetividad se divide, como pronto vamos a ver, en el mundo de lo consciente y en el de lo no-consciente. Mientras, la objetividad, que en historia corresponde a lo fáctico, se desdobla dialécticamente en el mundo de los hechos y en el de los no-hechos, como explicamos anteriormente. Examinemos primero ésta última.

Resulta muy sugerente el enfoque que realiza Ernst Bloch, marxista de fuerte influencia hegeliana, que inspiró con su "filosofía de la esperanza" a la llamada "teología de la esperanza", antecedente de la contemporánea "teología de la liberación". Pues bien, al pasado de "lo ya acontecido" y al presente de "lo que está aconteciendo" este autor le añadía la dimensión del futuro. Este era concebido como "lo que aún no ha acontecido". Un terreno en el que se mueven las ensoñaciones juveniles y el Ilamado sueño diurno, es la zona de "los sueños soñados despiertos", es la región de la utopía. La esperanza hace pie sobre este suelo. Para Bloch, el ser humano es constitutivamente proyecto, está lanzado hacia delante, su vida constituye la incesante búsqueda por lo que no es todavía pero que quiere llegar a ser, por lo que no ha alcanzado pero debe algún día conquistar. Es lo permanente de la esperanza humana: el sueño por una vida mejor, la utopía de un mundo mejor. El marxismo constituiría, según Bloch, la "utopía concreta". Marx situó, por primera vez, a la filosofía y al hombre en el horizonte del futuro.

Si atenuamos el carácter de "necesidad histórica" que el futuro pareciera tener en Bloch, -congruente con la idea de Marx de la necesidad histórica del socialismo y reforzamos la noción "posibilidad histórica", en lugar de su fórmula lo-que-aún-no-ha-acontecido vamos a proponer lo-que-podría-Ilegar-aacontecer. En defintiva, lo que "aún no es un hecho" pero podría llegar a serlo. Pero no era éste el sentido que le dimos al concepto de los nohechos. Este iba referido al pasado mientras aquí se trata del futuro. Para que lo fáctico quede completado con los no-hechos del pasado se debe agregar, a la noción de Bloch de lo-ya-acontecido, la expresión lo-que-no-llegó-a-acontecer. Es la perspectiva de la posibilidad real situada en el pasado. Para decirlo con términos sencillos, es "lo que pudo haber sido y no fue". Son las dos caras de la realidad histórica y que reflejan la ambivalencia de su facticidad.

En la ontología que Bloch construye, la estructura de lo-aúnno-acontecido corresponde con una estructura psicológica exclusiva de 
la especie humana: lo-aún-no-consciente. La teoría psicoanalítica descubrió la existencia del inconsciente, una región de la psique de lo que en su momento fue consciente pero quedó relegado, para la propia protección del yo, a una zona fuera de la conciencia. Son recuerdos olvidados, traumas borrados de la consciencia, experiencias o deseos que fueron reprimidos. Reaparecen en los sueños, enmascarados, disfrazados. De ahí que su análisis puede revelar contenidos de lo que está en el inconsciente, las claves de la represión y sus consecuencias patológicas. Bloch repara que en esta teoría freudiana el inconsciente queda circunscrito únicamente al pasado y reclama para el futuro la existencia del mismo. A la fórmula de Freud, que es la de lo-ya-noconsciente, opondrá la noción de lo-aún-no-consciente. ${ }^{12}$

Nuevamente nos toca completar la intuición de Bloch. Si en la conciencia que se orienta al futuro hay lo-aún-no-consciente o dicho de otra manera, lo-todavíainconsciente, para el pasado vamos a considerar la estructura de lo-yano-inconsciente. El pasado se vivió, una parte conscientemente y otra parte de forma inconsciente. La conciencia situada en el presente considera ese pasado y descubre ambas caras. Algo de lo que fue consciente ha dejado de serlo: tiene razón Freud. Pero también algo de lo que fue inconsciente hoy dejó de serlo. Es el agregado que le hacemos a Bloch: lo-ya-no-inconsciente.

De forma tal que, paralelamente al caso de lo fáctico, compuesto por los hechos y los nohechos, en el caso de la conciencia hallamos que está compuesta de dos áreas: la de lo consciente y la de lo inconsciente. Implica distinguir conceptualmente dos términos de semántica muy semejante: la conciencia y la consciencia. La primera contiene a la segunda. La subjetividad presenta esta complejidad en su desdoblamiento dialéctico. Al mismo tiempo, a la par de afirmar que existe una conciencia colectiva habrá que situar la afirmación de la existencia de un inconsciente colectivo. Esto se corresponde con la intuición de Hegel: "Un cierto grado de ignorancia en los hombres es necesario. Si éstos lo supieran todo, no harían nada y la historia no se realizaría." Ello no impide que, a posteriori, la ciencia alcance la comprensión y el proceso pueda ser analizado, digerido y asimilado, "elevado al nivel de la conciencia". La conciencia es con-ciencia.

La categoría-síntesis que buscamos debe dar cuenta, por lo tanto, de la dualidad de lo material y lo espiritual, de lo objetivo y lo subjetivo, de los hechos y los no-hechos, de lo consciente y lo inconsciente. Porque todo ello está presente y es constitutivo de eso que llamamos historia. Señalemos, por último, que 
su posibilidad teórica arranca de la doble perspectiva que el proceso histórico sugiere por sí mismo: se presenta como proceso objetivo que consiste en un conjunto de hechos, pero también como un proceso subjetivo compuesto por una serie de acciones humanas. Antonio González ha podido estructurar una nueva filosofía primera a partir de lo que él denomina "la verdad simple de nuestros actos". ${ }^{13}$ En este otro terreno, que es el de la teoría o filosofía de la historia, inversamente, hay que elaborar conceptualmente desde "la verdad compleja" de las acciones humanas. En vez de considerar el acto humano libre de toda mediación, examinarlo desde la totalidad y complejidad de las múltiples mediaciones que interactúan en la historia.

\section{La categoría "el signo de los tiempos" como concepto-síntesis}

La categoría teórica que aquí proponemos para caracterizar al proceso histórico y a su evolución, a su dinámica histórica general, hemos decidido denominarla "el signo de los tiempos". Constituye una innovación en la teoría y habrá que mostrar en qué forma se ha construido y, sobre todo, cómo funciona en el proceso histórico concreto que se va a analizar y del cual ha surgido, como respuesta a la necesidad de herramientas teóricas adecuadas. Lo primero, no obstante, es mostrar de qué herencia es deudora, en qué otros planteamientos se inspira y se apoya. Vamos a proceder por tres niveles sucesivos: el semántico, el conceptual o de contenido y el metodológico.

En primer lugar, las palabras escogidas para nombrar a nuestra categoría significan la recuperación semántica de la expresión cristiana que anteriormente expusimos. Hemos hecho la opción por el uso en singular, en lugar de la forma plural preferida por los teólogos, como un recurso para diferenciarla y también porque parece más adecuada a nuestros propósitos. No buscamos una multiplicidad de "signos" en la época, sino más bien un único "signo", que nos permita caracterizar un período concreto y distinguirlo del siguiente. Por lo demás, parece indicada la apertura y diversidad de contenido que la expresión teológica sugiere. Dejamos recogida, de esta forma, en nuestra categoría teórica central, la tradición del pensamiento cristiano y hecha explícita la deuda que con algunos de sus representantes, de manera especial con Ignacio Ellacuría, intelectual y biográficamente tenemos.

En segundo lugar, con la expresión "el signo de los tiempos" 
estamos en principio coincidiendo conceptualmente con las tres tradiciones que expusimos antes: la marxista, la hegeliana y la cristiana. Las tres son fuentes teóricas para nuestra categoría. En ella se recoge lo que anteriormente mencionamos como contenido en cada una de ellas. De la concepción marxiana "factor dominante" hemos dicho que hacía referencia a las ideas, concepciones, actitudes, aspiraciones, valores y prejuicios. De la expresión hegeliana "el espíritu de la época" comentamos que se refiere a la sensibilidad, actitud, visión, esperanza y convicción. De la fórmula cristiana "los signos de los tiempos" se nos decía que incluía los acontecimientos, exigencias, deseos, esperanzas y aspiraciones. Tienen las tres mucho en común y con todas coincidimos en la indicación de su contenido.

Ahora bien, lo que necesitamos es precisión conceptual y superar el nivel de la simple descripción. Es decir, tenemos que definir nuestra categoría. Ir más allá de enumerar su contenido y delimitar su alcance, ponerle límites, contornos, finitud. En eso consiste la labor de "definir". En superar "lo indefinido", lo que no tiene un borde que lo limita y lo delimita. Ante esta necesidad, nos inclinamos por recoger del marxismo la propuesta de "factor dominante" y apoyarnos en ella para nuestra elaboración conceptual de "el signo de los tiempos". Este se corresponderá con el elemento que actúe "dominando" durante un determinado período, en la misma medida que utilizaba Marx su concepto de factor dominante. Es decir, concebido como una forma de determinación directa, en primera instancia. Recogemos asimismo su idea de que otro componente, actuando como "factor determinante", determina al anterior y se constituye entonces en "sobredeterminación" o determinación en segunda instancia. La innovación consiste en aplicar el esquema, no a grandes períodos, de siglos, sino a breves períodos de unos pocos años. Esa diferente dimensión distorsiona y cambia muy acentuadamente el funcionamiento teórico de las piezas propuestas en el marxismo.

En tercer lugar, la inspiración metodológica principal la hemos encontrado en Hegel Se debe a que hemos concebido "el signo de los tiempos" como una categoría dialéctica y debíamos escoger entre estos dos modelos de dialéctica: el hegeliano y el marxista. Es conocido que Marx fue deudor de Hegel en lo que respecta a su método dialéctico. Así lo reconocía explícitamente él mismo: "La dialéctica de Hegel estaba de cabeza y había que darle vuelta para ponerla sobre sus pies". Es decir, la dialéctica histórica no se fundamenta en la cabeza, en el pensamiento, como había creído el idealista Hegel. En otro fragmento Marx reconoció que la "inversión" de la dialéctica hegeliana era más complicada y con ma- 
yores efectos teóricos que el simple giro que sugería antes. Habla ahora de un "darle vuelta como se hace con un guante". En tal operación ya no se trata sólo de que lo de arriba quede abajo y lo de abajo arriba, sino que en esta imagen lo interior pasa a ser exterior y viceversa. No solamente. ¡Démosle vuelta a un guante para comprobarlo! Lo que estaba a la derecha ahora quedó a la izquierda y a la inversa; si el guante es de la mano derecha, al darle vuelta queda con el pulgar al otro lado, ha pasado a ser un guante izquierdo. La idea es que la inversión altera los contenidos y el modo de funcionamiento del modelo teórico. Por lo tanto, tampoco para nosotros será cuestión secundaria decidirnos por uno u otro tipo de dialéctica. Veamos sus diferencias.

La primera parece sólo semántica. Marx se decidió por la poco afortunada expresión utilizada por Feuerbach: tesis, antítesis, síntesis. Desechó, no se sabe bien por qué, la que empleaba Hegel: afirmación, negación, negación de la negación. La fórmula hegeliana expresa un elemento clave en la dialéctica: la negatividad. La oposición de contrarios consiste entonces en la negación del uno por el otro, el opuesto emerge como resultado de un proceso donde el primer elemento se niega a sí mismo, el surgir de un tercer elemento se da como negación de los dos anteriores, de la afirmación primera y de su ne- gación (por eso es "negación de la negación").

La palabra "síntesis", en cambio, más sugiere una mezcla o combinación de los dos elementos primeros (tesis y antítesis) y es inferior semánticamente a la expresión de Hegel, que mantiene la fuerza de la oposición y el movimiento hacia delante propio del proceso dialéctico. Pero todo esto no le preocupó mayormente a Marx. Veamos por qué.

Para Marx era fundamental dejar enfatizado el momento de la oposición de contrarios, para lo cual le basta la terminología tesisantítesis. Explicita que la segunda surge de la primera, pero sobre todo, que se opone a ella, es "su anti". Se comprende por el uso que le dio Marx: la burguesía engendra, fatalmente, a la clase obrera y ésta se constituye en su antítesis. Es el momento de la contradicción y en él le interesa quedarse. No hay síntesis, ni negación de la negación, ni mucho menos "reconciliación" en un tercer momento dialéctico. Para sus postulados políticos le basta con esto, aunque el precio que paga es una dialéctica algo rudimentaria. Pero sucede que a nosotros sí nos interesa, y mucho, el tema de la reconciliación (la negación de la negación hegeliana) ya que nuestro proceso pasó por la negociación y los acuerdos. Tampoco nos inquieta una dialéctica del pensamiento, al contrario, pues parte de nuestra pro- 
blemática es explicar la transformación de la conciencia y de las ideas por parte de los actores políticos.

Aunque las tres fuentes teóricas manejan la dialéctica ("la dialéctica ya estaba en la Biblia", decía Ellacuría), hemos optado por el modelo hegeliano como metodología. En resumen, nuestra categoría "el signo de los tiempos" se llama como en la tradición cristiana, su contenido conceptual es semejante al "factor dominante" de la concepción marxista y su funcionamiento teórico está inspirado en la dialéctica hegeliana.

\section{Las dinámicas históricas y la definición del signo de los tiempos}

El proceso histórico de El Salvador en el período que estudiamos podría sintetizarse diciendo que supone el paso de la confrontación a la concertación. Primero una etapa en la que se va gestando la confrontación, hasta alcanzar ésta su forma más agudizada, la guerra. Después, durante el tiempo del conflicto, "misteriosas" dinámicas encauzarán el mismo hasta hacer que la confrontación se trueque en concertación. El misterio no hace sino reflejar la naturaleza dialéctica del proceso histórico. No es invento nuestro. No es capricho del investigador o ganas de ver ranas saltando. Verdaderamente el proceso real muestra, no sólo un salto dialéctico, sino una auténtica inversión por la cual la primitiva confrontación se transforma en su opuesto, en la negación de la confrontación. Es la concertación entre las partes beligerantes, la negociación y los acuerdos, el abrazo final de reconciliación entre quienes se habían hecho la guerra a lo largo de doce años.
El proceso enseña profusamente su rostro dialéctico a quien no cierre los ojos ni dude en mirarlo cara a cara. ARENA, el partido de la consigna "negociación es traición", es el que estando en el gobierno abrirá el proceso negociador y firmará los acuerdos de paz a nombre del Estado salvadoreño. No sólo eso. Este partido que nació con un rabioso anticomunismo, que creció coreando su himno según el cual "El Salvador será la tumba donde los rojos terminarán", sin embargo de hecho es el que legaliza al FMLN. En el propio Frente también se reflejan los avatares dialécticos, por ejemplo, al buscar el financiamiento de la agencia oficial estadounidense USAID, o al buscar la amistad de los políticos norteamericanos y del gobierno de Estados Unidos, después de haber sido el abanderado de "la lucha antiimperialista". Tampoco el PDC, el tercer gran actor del período, escapa al sino dialéctico. Su carismático líder, Napoleón Duarte, a quien el ejército le negó el triunfo electoral en 
1972, apresado y golpeado por los militares, expulsado del país y exiliado más de siete años, no obstante en 1980 promovió un pacto con la Fuerza Armada, gobernó con su apoyo y presidió la época de mayor represión de la historia del país en el marco de la contrainsurgencia.

Los ejemplos históricos pueden fácilmente multiplicarse. No parecen cosas lógicas y no lo son desde el punto de vista de la lógica tradicional. Pero encajan perfectamente en un esquema de lógica dialéctica. Tanto el proceso como sus actores reflejan las fórmulas de Hegel: A $==\mathrm{A}$ y a la vez $\mathrm{A}=/=\mathrm{A}$, es decir, $A$ es igual y al mismo tiempo distinto de sí mismo. Incluso se da la culminación de esta dialéctica, en un cuarto vértice en el cual lo que aparece es que $A==$ no $A$. En este caso, la cosa no sólo se diferencia de sí, sino que se ha constituido en su propia negación. Así se da en el proceso salvadoreño, en el que la confrontación no sólo se ha diferenciado o se ha hecho distinta, sino que se niega a sí misma, se ha transformado en su contrario dialéctico, ha devenido concertación.

Pues bien, nuestra categoría teórica "el signo de los tiempos" debe dar cuenta de esta dialéctica, mostrar las claves para comprender el mecanismo de oposición de contrarios y de la acción de la negatividad, la generación de la auténtica superación en historia. El signo de los tiempos, contemplado en su quietud, pareciera equivalente a la idea de factor dominante. Sería la determinación directa, en primera instancia, que domina así sobre el conjunto de acontecimientos y sobre la apreciación que de los mismos se hacen los hombres de la época. Pero considerado así es como si estuviera congelado, inmóvil, "como si el tiempo se hubiera suspendido". Impensable para una categoría histórica, ya que la historia es cambio, consiste fundamentalmente en el movimiento, presupone el tiempo como el escenario donde transcurre el acontecer.

A este "signo de los tiempos" hay que descongelarlo, dejarlo libre en su movimiento, concebirlo como inquietud. Dejarlo fluir en el tiempo, para que nos muestre así en qué consiste verdaderamente. Es como una cascada, incapaz de ser capturada en su fuerza y vitalidad por el cuadro inmóvil del pintor. Porque la catarata consiste exactamente en lo contrario de la fijación a que el artista la fuerza. De manera tal que, si nos preguntamos por el signo de los tiempos en un determinado momento histórico, contestaremos como con una fotografía, instantánea y nítida, pero muy poco fiel a la verdad. Será preferible un video, una filmación, capaz de mostrárnoslo en su evolución y movimiento, aunque tal vez la imagen pierda algo de nitidez. No obstante, será la que guarde mayor fidelidad hacia el proceso real, el cual se presenta como un gran caudal de hechos 
históricos, cual avalancha de acontecimientos que se precipita en el cauce de la historia.

Esto es así porque el concepto "signo de los tiempos" es en realidad inseparable de lo que es "el cambio en el signo de los tiempos". Es propio de la filosofía de la historia: la cosa cambia pero, al mismo tiempo, la cosa consiste en el cambio. No admiten pensarse separadamente, la cosa por un lado y el cambio en la cosa por el otro, como si el cambio fuera algo exterior, que le sobreviniera de afuera. Sólo el pensamiento dialéctico da cuenta de este modo de funcionamiento de la categoría "signo de los tiempos", que se corresponde con el movimiento dialéctico del proceso. "El hecho es sólo el cadáver -sentenciaba Hegel- que la tendencia deja tras de sí." No podemos considerar los hechos aisladamente. Por sí solos no explican nada. Hay que ver el hecho en tensión con lo que todavía no es un hecho. Hay que entrar a la dialéctica de la tendencia.

Por lo tanto, el signo de los tiempos es en sí dinámico y consiste en su propia dinámica. Es la dinámica histórica general que preside y sintetiza el proceso histórico efectivo. Es la serie de acontecimientos, de hechos históricos, de voluntades y de acciones humanas, que constituyen juntamente el material de la historia. Pero este abigarrado conjunto ha de ser agrupado en el análisis, conforme a su trama real de relaciones, a fin de poder ser captado y comprendido. De modo que en lugar de una dinámica general tendremos unas dinámicas específicas, fruto del agrupamiento de los diferentes componentes.

Definiremos dinámica histórica de la siguiente forma: "es el movimiento específico del conjunto de iniciativas, actuaciones y hechos generados por los actores políticos y por los sujetos históricos en un ámbito concreto de la actividad social". Para nuestro caso hemos identificado las dinámicas siguientes: económica, política, social, ideológica y militar. Podríamos pensar en otras posibles dinámicas históricas, dependiendo del objeto de estudio y de la problemática a investigar: diplomática, cultural, migratoria, religiosa, etc. Ha de ser el investigador quien, en dependencia de su problema y sin forzar lo que le ofrece el material que estudia, decida con qué dinámicas va a operar y realice el agrupamiento de los diversos componentes en la manera más conveniente.

Nuestra categoría queda ahora definida como una dinámica de dinámicas, como aquella dinámica histórica general que consiste en la relación entre las dinámicas específicas que hemos definido como esferas diferenciadas de la actividad social. El "signo de los tiempos" puede definirse así: "el movimiento dialéctico que se establece por la interacción y relación dialéctica 
entre las diversas dinámicas históricas". Por su misma naturaleza presenta una doble faz: objetiva, en tanto en cuanto se trata de hechos y acontecimientos en su completa facticidad; subjetiva, por tratarse de acciones humanas y de la percepción que de las mismas tienen los sujetos que protagonizan la historia.

\section{El signo de los tiempos como categoría dialéctica: su funcionamiento teórico}

Al referirnos al signo de los tiempos de un período determinado hacemos referencia a la objetividad de los acontecimientos como también a la vivencia y percepción de los mismos, que son subjetivas, a la ideología imperante en la época tanto como a la serie de elementos fácticos que son su sustrato y su campo operaciones. En segundo lugar, debe percibirse el signo de los tiempos como algo en sí dinámico, que se transforma y continuamente está gestando su propia mutación, que jamás existe en forma estática.

La mutación del signo de los tiempos, su cambio, es fruto de la interacción dialéctica de las dinámicas históricas que lo definen. Corresponde al cambio de coyuntura histórica. Definimos "coyuntura" como "una determinada articulación de las distintas dinámicas históricas, que se mantiene durante un limitado período de tiempo". El proceso aparece como una sucesión interminable de coyunturas, que se siguen unas a otras, de manera ininterrumpida. El signo de los tiempos cabalga sobre ellas, avanza entre ellas, como el surfista lo hace sobre su tabla, sin ser tragado por el oleaje, venciendo las olas en la medida que no las resiste, sino que se deja arrastrar por ellas. De manera semejante se abre paso el signo de los tiempos, siendo que su movimiento y alteración indica el cambio de coyuntura, el encadenamiento de unas coyunturas con otras en el marco del desarrollo del proceso histórico.

El juego dialéctico que se establece entre las diferentes dinámicas históricas adopta, en nuestra categoría teórica, la forma de la determinación. Así como Marx se refería a un factor determinante y uno dominante, aquí hablaremos de una dinámica dominante y de una dinámica determinante. La dominante, en su relación con las demás dinámicas, va a ejercer sobre ellas una determinación directa, mientras la dinámica determinante lo hace en segunda instancia. Es ésta última en su papel de sobredeterminación la que determina cuál de ellas va a asumir el papel dominante. La relación dialéctica entre la dinámica determinante y la dominante preside el signo de los tiempos y lo hace avanzar hacia su cambio y transformación. 
Si se examina en su detalle la relación dialéctica establecida observaremos que podemos descomponerla en cinco momentos sucesivos. El primero es el que muestra cómo una de las dinámicas históricas ejerce su papel de factor determinante "empujando" a otra de ellas al primer plano de la escena histórica, al incrementar su importancia y su acción, y la determina a constituirse en factor dominante del período. Pasa a dominar el escenario y desde su esfera de actividad domina efectivamente sobre las demás dinámicas históricas incluyendo a la que juega el papel de factor determinante. Pero en el primer momento no hay entre ambas dinámicas, dominante y determinante, conflicto alguno sino que se aprecia correspondencia, colaboración y apoyo mutuo.

Esta inicial armonía queda rota en un segundo momento. Surge la contradicción entre dinámica dominante y dinámica determinante. La oposición estriba en que el factor dominante, desde su propia autonomía, establece la superioridad jerárquica de la determinación en primera instancia sobre la dinámica determinante. Asume ahora como el contrario dialéctico de la afirmación primera que había establecido ésta pese a haber surgido de su seno y por su impulso. Lo que afirmaba la dinámica determinante es ahora negado por la dominante, la cual ejerce sobre aquélla la acción de la negatividad, con la carga de subver- sión que ello implica. Este segundo momento es plenamente dialéctico y presupone el momento anterior, donde la contradicción estaba sólo en estado latente.

El tercer momento se distingue por el relieve que toma una tercera dinámica histórica, como consecuencia y en reacción a la oposición contradictoria que hemos descrito antes y que en su esfuerzo de resolución tensiona al conjunto del escenario. Efecto de aquella dialéctica es la preponderancia tomada ahora por esta dinámica que podemos denominar resultante (o síntesis o negación de la negación). Viene, con su propia actividad, desde su esfera concreta de acontecimientos e iniciativas, a exacerbar la contradicción de las dinámicas determinante y dominante. Su acción resulta en apoyo de ésta última, ayuda a resolver la contradicción a favor de la dominancia de la dinámica dominante. Ésta acaba siendo claramente vencedora sobre el factor determinante, imponiendo su signo sobre el proceso en este momento del mismo. Pero queda en deuda, en el fondo es dependiente, de la dinámica resultante o tercer elemento de la tríada dialéctica que se ha configurado.

Esta dependencia presagia ya el cuarto momento dialéctico: la dinámica síntesis aparece como auténtica "negación de la negación". Se ha relacionado de manera contradictoria con la dinámica determinante 
en el momento anterior; ahora lo hará con el factor dominante. Es la coronación del movimiento dialéctico, en el que la primera oposición de contrarios resulta superada, por la misma lógica de su oposición, por un tercer elemento que viene a desplazar ambos extremos y su propia contradictoria relación del centro de la acción. La dinámica resultante anula a las dos anteriores, determinante y dominante, y opaca asimismo su misma relación común. El signo de los tiempos queda así desplazado hacia este tercer componente de la tríada dialéctica.

El quinto y último de los momentos dialécticos en que se descompone esta relación está ya prefigurado por lo dicho anteriormente. La dinámica síntesis, que aparece como la resultante de aquella dialéctica y en lo que "resulta" el signo de los tiempos, es negación de la negación en su sentido pleno. Como negación negada que es, no puede consistir sino en una afirmación. De modo tal que ahora aquel tercer elemento se configura como el primer elemento de una nueva relación dialéctica, como lo que el proceso histórico se afirma de sí mismo, como la nueva afirmación. Ésta determinará en primera instancia en cuál otra dinámica histórica se apoya, impulsándola. Ésta vendrá en su auxilio y en la medida que se asiente como nueva dinámica dominante se retirará al segundo plano, reduciéndose al papel de segunda instancia, al rol de simple factor determinante. Este quinto momento dialéctico preanuncia, por tanto, la configuración de una nueva tríada dialéctica hacia la que se va a desplazar el signo de los tiempos.

Si no se procede con todo el detalle que nos hemos impuesto en esta descripción bien podría considerarse que son tres los momentos esenciales: el primero, el de la relación dialéctica entre factor determinante y factor dominante, el segundo, el surgimiento de un tercer elemento que completa la tríada dialéctica y se relaciona contradictoriamente con los dos anteriores, el tercero, el momento en que la relación en sí resulta superada y se constituye la negación de la negación como verdadera afirmación. La síntesis será así la nueva tesis, destinada a ser negada y superada en el posterior movimiento dialéctico. 


\section{Notas}

1. Ellacuría, Ignacio: "El objeto de la filosofía”, pág. 86, en Ellacuría: Filosofía de la realidad histórica, UCA, San Salvador, 1990.

2. Dada Hirezi, Héctor: "La transición salvadoreña y los partidos políticos", VV. AA.: Proceso electoral y democratización, Cuaderno de Trabajo \#6, julio 1994, FLACSO, El Salvador.

3. Pleitez, Rafael Antonio: “¿Por qué ocurrió una guerra civil en El Salvador y no en Honduras?”, revista Realidad N45, mayo-junio 1995, UCA, San Salvador.

4. Para una ampliación de la temática puede verse nuestro estudio: Ribera, Ricardo: Para leer a Hegel. Filosofía para principiantes, Ediciones para el debate, Talleres Gráficos UCA, San Salvador, 1998.

5. Marx, Karl: Prólogo a la Crítica de la filosofía del Estado de Hegel, Ed. Grijalbo, México, 1968.

6. Ellacuría, Ignacio: "Historicidad de la salvación cristiana”, pág. 328, en Ellacuría/Sobrino: Mysterium Liberationis. Conceptos fundamentales de la teología de la liberación, Tomo I, UCA, San Salvador, 1990.
7. Ibid: págs. 330 y 338. Cita en nota al pie la siguiente bibliografía: Chenu, M.D.: Les signes des temps, NRT \#1, 1965; McGrath, M.: "Los signos de los tiempos en América Latina hoy”, en Los textos de Medellin, San Salvador, 1977.

8. Sobrino, Jon: "La teología y el principio liberación”, pág. 120, Revista Latinoamericana de Teología N³5, mayo-agosto 1995, Centro de Reflexión Teológica, UCA, San Salvador.

9. Ellacuría, opus cit., pág. 347.

10. Marx, Karl: "XI Tesis sobre Feuerbach”, en Manuscritos económicofilosóficos de 1844, Ed. Grijalbo, México, 1968.

11. El tema es analizado en detalle en Harnecker, Marta: La revolución social: Lenin y América Latina, Ed. Siglo XXI, México, 1985.

12. Sobre la filosofía de este pensador véase el interesante estudio de Gómez Heras: Utopia y sociedad en Ernst Bloch, Ed. Sígueme, Salamanca,

13. González, Antonio: Estructuras de la praxis. Ensayo de una filosofía primera, Trotta, Madrid, 1997. 